\title{
Progress in the Control of Hepatitis B Virus Infection among Children in Indonesia
}

Takako Utsumi ${ }^{1,2^{*}}$, Maria I Lusida ${ }^{1}$, Yoshihiko Yano ${ }^{2}$, Priyo B Purwono ${ }^{1}$, Mochamad Amin ${ }^{1}$, Soetjipto ${ }^{1}$, Hak Hotta ${ }^{2}$ and Yoshitake Hayashi ${ }^{2}$

${ }^{1}$ Indonesia-Japan Collaborative Research Center for Emerging and Re-emerging Infectious Diseases, Institute of Tropical Disease, Airlangga University, Surabaya, Indonesia

${ }^{2}$ Center for Infectious Diseases, Kobe University Graduate School of Medicine, Kobe, Japan

*Corresponding author: Utsumi T, Center for Infectious Diseases, Kobe University Graduate School of Medicine, Kobe, Japan, Tel: +62-31-594-0917; E-mail: tutsumi@people.kobe-u.ac.jp

Received date: 02 July 2014; Accepted date: 21 Aug 2014; Published date: 25 Aug 2014

Copyright: (c) 2014 Utsumi T, et al. This is an open-access article distributed under the terms of the Creative Commons Attribution License, which permits unrestricted use, distribution, and reproduction in any medium, provided the original author and source are credited.

\begin{abstract}
Indonesia introduced a universal vaccination program for the hepatitis B virus (HBV) in 1997; however, the longterm efficacy of the HBV vaccination has not yet been established among children. We conducted serological and genetic surveys among children in East Java, Indonesia to assess the progress of the national immunization program. A total of 185 pre-school children aged 1-5 years old born between 2006 and 2011 were enrolled in this study. A total of 150 children (81.1\%) were completely vaccinated, and the birth dose coverage within 7 days after birth was $74 \%$. None of the children were positive for the hepatitis B surface antigen (HBsAg), while 4 children were infected with occult HBV. The prevalence of anti-HBs antibody positive was only $26.5 \%$, and positive prevalence and titer of anti-HBs decreased with age. The universal HB vaccination is considered effective in preventing HBV infection in children in this study site, while the protective rate remains insufficient. An effective strategy needs to be developed in order to detect all vaccination failure cases. To achieve complete protection, it would be necessary to consider an appropriate time for the first dose and booster dose.
\end{abstract}

Keywords: Hepatitis B virus; Pre-school children; Universal vaccination; Indonesia

\section{Introduction}

The endemicity of hepatitis B virus (HBV) infection was previously reported to be moderate to high in Indonesia [1]. HBV infection is generally acquired during the first five years of life in countries with a high prevalence of chronic HBV infection [2]. Unless vaccinated at birth, the majority of children born to infected mothers become chronically infected [3].

A safe and effective vaccine against HBV infection has been available since 1982, and was recommended by the World Health Organization (WHO) for administration to all infants from 1992. Administration of the hepatitis B (HB) vaccine soon after birth, preferably within 24 hours, is crucial to prevent vertical transmission, and failure to administer this vaccine in a timely manner has been shown to reduce the impact of immunization [4,5]. A total of 179 countries now routinely vaccinate children against $\mathrm{HBV}$ and an elimination target has been set at less than $1 \%$ infection prevalence in pre-school children in endemic areas [6,7].

However, previous studies have demonstrated difficulties in reaching mothers and their newborn infants around the time of birth in developing countries in which a significant proportion of births occur at home, especially in locations far from the health facility $[1,4,8]$.

The HB universal vaccination was introduced in Indonesia in 1997, with the Indonesian government attempting to ensure that every newborn is vaccinated against $\mathrm{HBV}$ infection during the first 7 days of life. The Uniject device, a pre-filled, single use injection device that can be used instead of a traditional syringe and needle, was shown to be crucially important to the $\mathrm{HB}$ universal vaccination program in Indonesia $[4,9,10]$. However, the prevalence of HBV infection among children after implementation of the vaccination program has yet to be determined. We conducted serological and genetic surveys among preschool children in the community of East Java.

\section{Materials and Methods}

\section{Study population}

Blood samples were collected from a total of 194 pre-school children aged 1-5 years old born between 2006 and 2011 who were admitted to the health program for pre-school children in Posyandu (a satellite health center that delivers vaccinations and nutrition) in the East Perak area (population; 72,744), East Java in January 2011. Of the 194 children, 185 (mean age $3.6 \pm 1.2$ years old, 106 boys and 79 girls) with vaccination cards were enrolled in this study. The vaccination histories of these children were obtained from vaccination cards provided by the local health office. A questionnaire including demographic data and the place of birth was given to the guardians of the children. Written informed consent was provided by the guardians and a research permit was also obtained from the local health office. The study protocol was reviewed and approved by the Ethics Committees of Kobe University in Japan and Airlangga University in Indonesia.

\section{Universal HB vaccination in Indonesia}

The HB vaccination schedule in Indonesia is shown in Table 1. Indonesia is currently the only country with a national policy of using the $\mathrm{HB}$ vaccine in the Uniject presentation, including outside the cold 
chain. Uniject has been used as a birth dose, and is recommended within 7 days of birth in Indonesia $(1,10)$. Uniject and the DTP-HB combination vaccine are manufactured by Biofarma in Indonesia, and these recombinant vaccines contain a non-infectious hepatitis $\mathrm{B}$ viral antigen that is produced in yeast cells using recombinant DNA technology. In the study sites, Uniject and the DTP-HB combination vaccine have been employed for children since 2005 .

\begin{tabular}{|l|l|}
\hline Vaccine & Age \\
\hline HB $0^{*}$ & Within 7 days of birth \\
\hline BCG, Polio 1 & At 1 month of age \\
\hline DPT/HB ${ }^{* *}$ 1, Polio 2 & At 2 months of age \\
\hline DPT/HB 2, Polio 3 & At 3 months of age \\
\hline DPT/HB 3, Polio 4 & At 4 months of age \\
\hline Measles & At 9 months of age \\
\hline
\end{tabular}

Table 1: Vaccination schedule in Indonesia. ${ }^{\star}$ first dose of the Hepatitis $\mathrm{B}$ vaccine, Uniject is used, ${ }^{* *}$ the DPT and Hepatitis combination vaccine.

\section{Serological markers of HBV infection}

Serum samples were tested for HBsAg by Reversed Passive Hemagglutination (R-PHA) (Mycell II HBsAg; Institute of Immunology, Tokyo, Japan) and also the anti-HBs antibody by Enzyme-linked immunosorbent assay (ELISA) (Hepalisa anti-HBsAg: Indec Diagnostics, Jakarta, Indonesia). The cut-off level of the antiHBs antibody was decided as $10 \mathrm{mIU} / \mathrm{ml}$. To differentiate vaccineinduced antibodies from naturally acquired antibodies in children, the prevalence of the antibody to the hepatitis B core antigen (anti-HBc antibody) was assessed by PHA (Mycell anti-rHBc; Institute of Immunology, Tokyo, Japan).

\section{Sequence analysis in the a determinant region in $\mathrm{HBsAg-}$ negative children}

After being assayed for the $\mathrm{HBV}$ serological status, 54 serum samples that were negative for HBsAg but positive for either anti-HBs or anti-HBc were subjected to $\mathrm{HBV}$ genetic analysis to identify surface antigen variants. After serological testing, serum samples were stored at $-20^{\circ} \mathrm{C}$ until genetic testing. DNA was extracted from $100 \mu \mathrm{l}$ of serum samples using a DNA extractor kit (QIAamp DNA Blood Mini Kit; QIAGEN, Tokyo, Japan). The presence of HBV DNA was assayed by single PCR using the primers HBSF2; 5'CTTCATCCTGCTGCTATGCCT-3' and HBSR2; 5'AAAGCCCAGGATGATGGGAT-3' corresponding to the determinant region, which is involved in antigenicity, as previously described [11]. Amplified fragments were directly sequenced using the Big Dye Deoxy Terminator cycle sequencing kit with an ABI PRISM 310 genetic analyzer (Applied Biosystems, Foster City, CA). The HBV nucleotide sequences of the $\mathrm{S}$ gene were translated to amino acid (aa) sequences and aligned with reference sequences. The aa substitutions in the a determinant region (aa124-147) of the $S$ genes were then analyzed.

\section{Confirmation of HBsAg in HBV DNA-positive children}

To minimize the possibility of false-negative results for HBsAg, an enzyme-linked immunosorbent assay (ELISA) (Hepalisa HBsAg: Indec Diagnostics, Jakarta, Indonesia) and an immunochromatography method based on the principal of an enzyme immunoassay (EIA) (Espline HBsAg; Fuji Rebio, Tokyo, Japan), were used for samples that were HBsAg negative by RPHA, but HBV DNA positive by PCR.

HBV genotyping. HBV genotypes/subgenotypes were determined using a phylogenetic tree of the $S$ region. Reference sequences were retrieved from the DNA DataBank of the Japan/European Molecular Biology Laboratory/GenBank database. Alignments were performed using CLUSTAL X software, a phylogenetic tree was constructed using the neighbor-joining method, and bootstrap resampling was performed 1,000 times. Analyses were conducted using the Molecular Evolutionary Genetics Analysis (MEGA) software program.

\section{Statistical analysis}

Significance was evaluated by the chi-square test or Fisher's exact test for categorical variables. The independent t-test was used for continuous variables, as appropriate. A P value $<0.05$ was considered significant.

\section{Results}

\section{Coverage and timing of the birth dose $\mathrm{HB}$ vaccine in children}

Of the 185 children with vaccination data, 166 (89.7\%) were vaccinated by the first dose $\mathrm{HB}$ vaccine (Uniject). The timing of the birth dose $\mathrm{HB}$ vaccine by days after birth in the present study was shown in Figure 1. Of these 166 children, 53 (31.9\%) and 63 (38.0\%) were vaccinated within 24 hours and 1-6 days after birth, respectively. Overall, 116 of 166 children (69.9\%) were administered the birth dose within 7 days after birth, whereas the remaining 50 (30.1\%) children were administered the first dose one week or later after birth. A total of 150 children $(81.1 \%)$ completed the $\mathrm{HB}$ vaccination program scheduled by the Indonesian government (a birth dose $\mathrm{HB}$ vaccine by Uniject and $3 \mathrm{DTP} / \mathrm{HB}$ combination vaccines). Of the 150 children who completed the $\mathrm{HB}$ vaccination program, the coverage of the birth dose vaccine within 24 hours, 1-6 days, and 7 days or more after birth were $34.0 \%(51 / 150), 40.0 \%(60 / 150)$, and $26.0 \%(39 / 150)$, respectively. In total, coverage within 7 days after birth was $74 \%(111 / 150)$.

\section{Birthplace and first dose coverage}

Of the 157 children with known birthplaces, 92 (58.6\%) were born in a hospital, $56(35.7 \%)$ were born outside of a hospital with the help of a skilled birth attendant (SBA), and 9 (5.7\%) were born at home without a SBA. The birth dose coverage with timelines was summarized depending on the birthplace, as shown in Table 2. No significant difference was observed in the birth dose coverage within 24 hours of being born between birthplaces. However, the birth dose coverage within 7 days at home without a SBA was significantly lower $(55.6 \%)$ than that at a health facility, at home with a SBA $(92.9 \%$, $\mathrm{p}=0.009)$, and at a hospital $(87.0 \%, \mathrm{p}=0.03)$. 


\section{Serological status among children}

Serological tests for HBV infection revealed that 49 (26.5\%) and 6 (3.2\%) out of 185 children were positive for anti-HBs and anti-HBc, respectively. None of children were positive for HBsAg. The positivity of anti-HBs gradually decreased from $60.0 \%$ at 1 year of age to $12.0 \%$ at 5 years of age. The mean titer of anti-HBs among children gradually decreased from $462.0 \mathrm{mIU} / \mathrm{ml}$ at 1 year of age to $180.5 \mathrm{mIU} / \mathrm{ml}$ at 5 years of age (Figure 2). Forty-seven (95.9\%) of the 49 children who were anti-HBs positive were negative for the anti-HBc antibody, which suggested successful immunization by the $\mathrm{HB}$ vaccine.

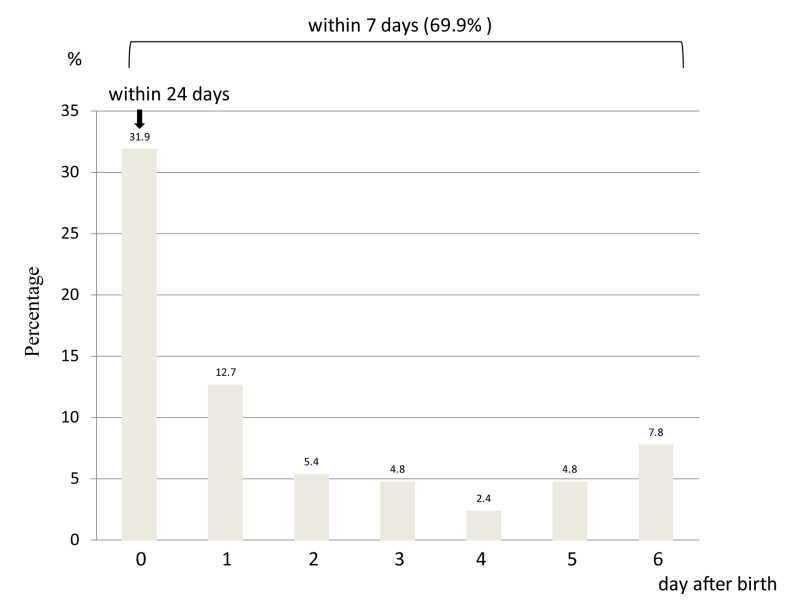

Figure 1: Timing of the first dose of the hepatitis $B$ vaccine according to days after delivery.

\begin{tabular}{|l|l|l|l|l|}
\hline Place of birth & $<\mathbf{2 4}$ hours & $<\mathbf{7}$ days $^{\star \star *}$ & $\geq \mathbf{7}$ days & Total \\
\hline At home, no SBA & $3(33.3 \%)$ & $5(55.6 \%)^{\text {a,b }}$ & $4(44.4 \%)$ & $9(100 \%)$ \\
\hline $\begin{array}{l}\text { HF } \\
\text { SBA }\end{array}$ & $18(32.1 \%)$ & $52(92.9 \%)^{\mathrm{a}}$ & $4(7.1 \%)$ & $56(100 \%)$ \\
\hline Hospital & $32(34.8 \%)$ & $80(87.0 \%)^{\mathrm{b}}$ & $12(13.0 \%)$ & $92(100 \%)$ \\
\hline
\end{tabular}

Table 2: Timelines of the first dose among 157 children with known birthplaces. ${ }^{*} \mathrm{SBA}$, skilled birth attendant, ${ }^{* *} \mathrm{HF}$, health facility, ${ }^{* *}<$ 24 hours was included. a, $\mathrm{p}<0.009, \mathrm{~b}, \mathrm{p}<0.03$.

\section{Detection of HBV-DNA and mutations in the $S$ gene}

HBV-DNA was detected in 4 (7.4\%) out of 54 children who were $\mathrm{HBs} A g$ negative but positive for either anti-HBs or anti-HBc, which indicated occult $\mathrm{HBV}$ infection. All 4 children were completely vaccinated by the $\mathrm{HB}$ vaccine. $\mathrm{AA}$ substitutions in the determinant region were detected in 3 children, as shown in Table 3. The HBV strains of children PTA142 and PTA148 had 3 substitutions, T126I, M133L, and T143S, and the PTA26 strain had the substitution Q129H. PTA198 was a wild type strain. Three (PTA26, PTA 142, and PTA198) of the 4 children were positive for anti-HBs, and vaccinated first dose within 7 days as scheduled (Table 3). The status of the four children with undetectable HBsAg was suggested as follows: PTA26 and PTA142 had vaccine escape mutants; PTA148 was naturally infected with vaccine escape mutants, and PTA198 had recovered from wildtype HBV infection. The HBV genotypes were successfully determined for 3 children. HBV genotype B (HBV/B) was identified in one child and $\mathrm{HBV} / \mathrm{C}$ was identified in 2 children, as shown in Figure 3.

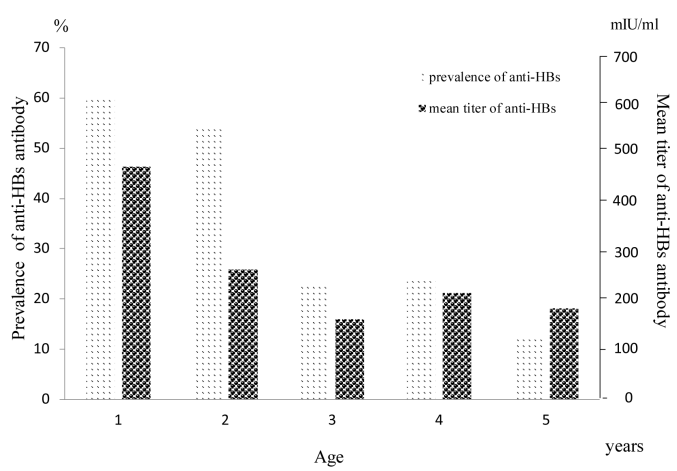

Figure 2: Amino acid alignment of the partial surface antigen including the alpha determinant region. The first line is the consensus sequence corresponding to an HBV subgenotype (B1; accession no. D23678) reference strain retrieved from the DNA DataBank of the Japan/GenBank database. Dots in the alignment indicate positions with amino acids identical to the HBV/B1 consensus sequence. The determinant region is indicated by a different color.

\section{Discussion}

The primary objectives of this study were to assess the status of HBV infection among pre-school children and profile the vaccination practice in East Perak area. Our study revealed that none of the 1-5 year old children who participated in this study were infected by HBV. This result is markedly lower than that among pre-school children in another area of Indonesia (Purwono et al, unpublished data). Since the prevalence of HBsAg among the general population in this area was $6.7 \%$ [12], children in this study were considered to be protected from either perinatal or horizontal transmission. However, these results cannot confirm a decrease in the prevalence of HBsAg because it has never been tested in pre-school children in this study site. Moreover, the overall positive rate of anti-HBs alone, which means immunized well due to the $\mathrm{HB}$ vaccine, was lower in this study population than those in other countries $[8,13]$.

\begin{tabular}{|l|l|l|l|l|l|l|}
\hline Subject & $\begin{array}{l}\text { Age } \\
\text { (years) }\end{array}$ & Sex & $\begin{array}{l}\text { Time of } \\
\text { the first } \\
\text { dose } \\
\text { (days) }\end{array}$ & $\begin{array}{l}\text { Anti- } \\
\text { HBs }\end{array}$ & Anti-HBc & $\begin{array}{l}\text { Amino acid } \\
\text { substitutions }\end{array}$ \\
\hline PTA26 & 4 & M & 7 & + & - & Q129H \\
\hline PTA142 & 2 & M & 0 & + & - & $\begin{array}{l}\text { T126I, } \\
\text { M133L,T143S }\end{array}$ \\
\hline PTA148 & 5 & M & 21 & - & + & $\begin{array}{l}\text { T126I, } \\
\text { M133L,T143S }\end{array}$ \\
\hline PTA198 & 3 & M & 4 & + & - & Wild \\
\hline
\end{tabular}

Table 3: Serology and amino acid substitution in completely vaccinated children with occult $\mathrm{HBV}$ infection. HBsAg: Hepatitis B surface antigen; HBV: Hepatitis B virus; Anti-HBs: Antibody to HBsAg; Anti-HBc: Antibody to the hepatitis B core antigen. 
Citation: Utsumi T, Lusida MI, Yano Y, Purwono PB, Amin M, et al. (2014) Progress in the Control of Hepatitis B Virus Infection among Children

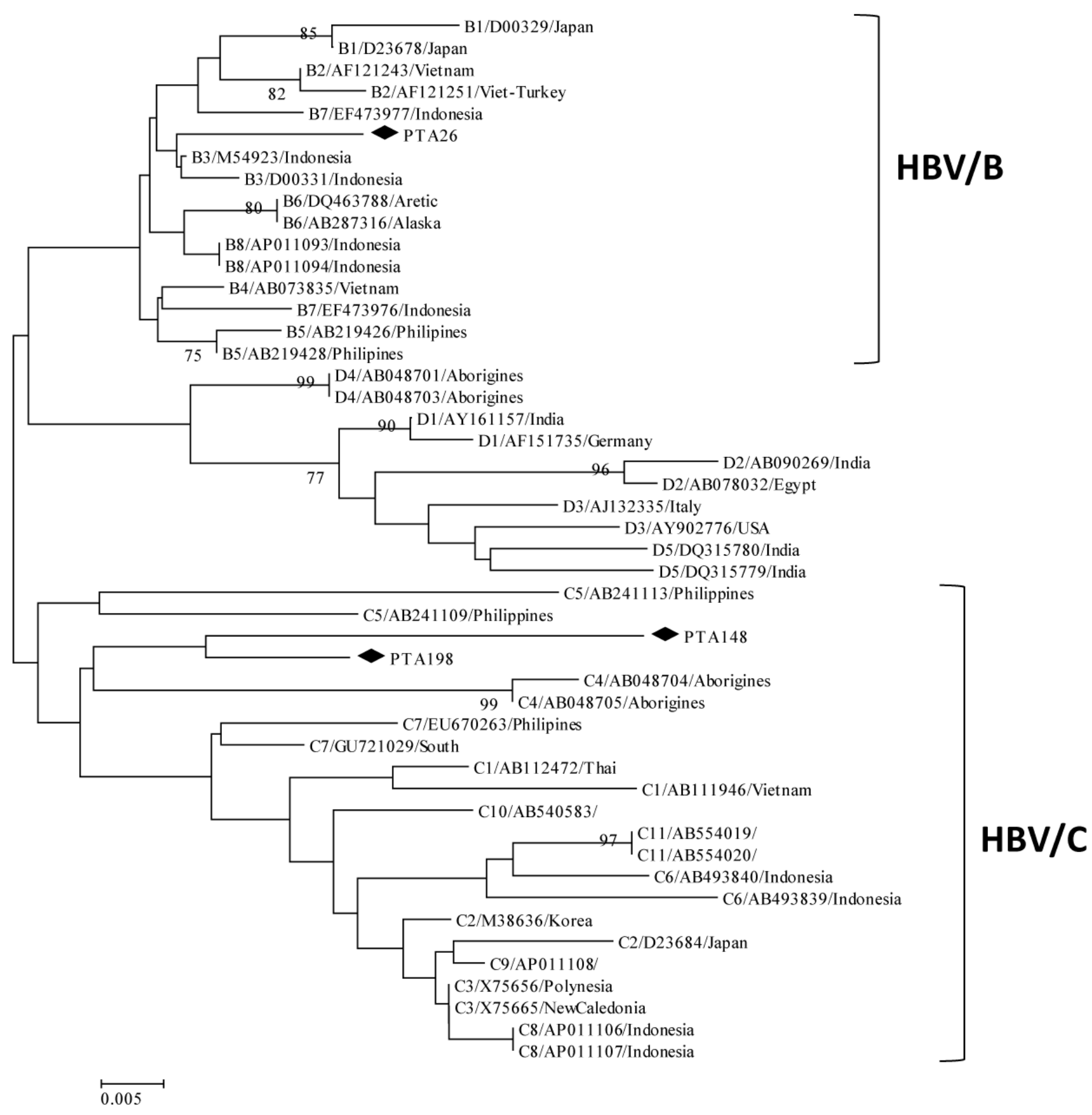

Figure 3: Phylogenetic trees based on the surface gene in hepatitis B virus (HBV) strains isolated from 3 children in this study, and 45 reference strains. Numbers in the tree indicate bootstrap reliability. The lengths of horizontal bars indicate the number of nucleotide substitutions per site. Isolates from the database are indicated by their accession number, and relevant country names have been added to each $\mathrm{HBV} / \mathrm{B}, \mathrm{HBV} / \mathrm{C}$, and HBV/D strain.

Vaccination coverage (defined as the percentage of children administered the complete $\mathrm{HB}$ vaccine in the present study; 1 Uniject and 3 DTP-HB combination) was higher ( $81 \%)$ in this study than in the $2013 \mathrm{WHO} / \mathrm{UNICEF}$ report in which $63 \% \mathrm{HB}$ vaccination coverage was achieved in all of Indonesia [14]. The prevalence of HBsAg was zero among pre-school children in the present study, which indicated that the local health office in this study site may have achieved the HBV elimination target of less than $1 \%$ infection in preschool children. On the other hand, the prevalence of HBV in school children aged 6-13 years old was $2.8 \%$ in the same area (Utsumi et al. unpublished data), which indicated that the risk of being infected with 
HBV was still present if children were not continually protected, especially in endemic areas including Indonesia.

The seropositive rate of anti-HBs at 1 year of age after completion of the $\mathrm{HB}$ vaccination program in the present study was inconsistent with the almost $100 \%$ reported in a previous study [15]. We suggested two possible reasons for the lower immune response in this study: a delay in administrating the birth dose vaccine and the loss of protective antibodies to HBV infection [16]. The birth dose coverage within 7 days after birth was $70 \%$ in the present study. Although enough data is not available on the timing of the birth dose in other areas in Indonesia, except for Southeast Sulawesi (39\%) in which $97 \%$ of deliveries occur at home [1], the local health office in this study site attempted to reach recommended targets set by the Indonesian government to administer the first dose within 7 days after birth. If we consider the birth dose coverage within 24 hours, a delayed birth dose may play a role in the low response of $30 \%$; however, children were not infected with HBV at least by 5 years of age. On the other hand, occult $\mathrm{HBV}$ infection (HBsAg negative but HBV DNA positive) was found in 4 children in this study, even though 3 of them were vaccinated first dose within 7 days after birth (one child within 24 hours). This suggests the importance to recognize the risk factors for vertical transmission during pregnancy [17].

The titer of the anti-HBs antibody gradually decreased with age in this study. A previous study revealed that the positivity of protective anti-HBs gradually decreased with age and reached undetectable levels by 12 years of age. Due to the loss of protection, these anti-HBsnegative children may be at a higher risk of HBV infection [18]. Moreover, Biofarma Indonesia reported that a booster dose is required every 5 years after the primary course of vaccination [19]. Therefore, the continuous monitoring of protection against HBV in school age children is needed in order to confirm the necessity of a booster dose; however, booster doses against HBV remain controversial because of the anamnestic response [20,21].

The WHO recommends that all infants should receive their birth dose of the $\mathrm{HB}$ vaccine as soon as possible after birth, preferably within 24 hours [22]. However, in the present study, the difference in the protection rates with hepatitis $B$ vaccine between the vaccination times, i.e., within 24 hours and 7 days after birth, is unclear because of the small sample size. In the present study, children delivered at home without a SBA had a significantly lower chance of being administered the birth dose vaccine than those delivered in a health facility or hospital. Although this study site is a small town in the second largest city (population; 3 million) in Indonesia and is more accessible to health facilities than other remote areas, $5.7 \%$ of newborn babies were born at home without a SBA. A timely birth dose for a baby delivered at home without a SBA requires the mother to visit a health facility within 7 days of delivery, which is possible in this study site. Improving facility delivery rates may help improve birth dose $\mathrm{HB}$ vaccination coverage by providing an opportunity to educate mothers of the need for vaccines [8].

Antibodies to HBsAg are mainly targeted to bind the amino acid hydrophilic region, referred to as the determinant of HBsAg. This provides protection against infection from all $\mathrm{HBV}$ genotypes and is responsible for the broad immunity afforded by the hepatitis vaccination $[23,24]$. Two escape mutants were identified in this study. The emergence of HBV S-gene mutants that may be able to escape the vaccine-induced response has been suggested. However, the overall impact of such mutants currently remains low, and they do not pose a public health threat or the need to modify established hepatitis B vaccination programs [25-27]. A comparison with previous studies performed in other countries showed that the most common escape mutant G145R is currently rare in Indonesia $[23,25]$.

Breakthrough infections in these immunized infants have been attributed to the timing of the vaccinations, especially the birth dose of the $\mathrm{HB}$ vaccine [13]. Other identified causes include inadequate vaccine storage, incomplete dosage, or improper administration $[1,24]$. Immune responses to vaccinations and the outcomes of HBV infection are also known to be influenced by the type of HLA allele [28]. Geographical and ethnic differences may also play a role [8,24].

In conclusion, the universal $\mathrm{HB}$ vaccination effectively prevented the transmission of HBV in children at least until 5 years of age in the present study; however, the protective rate remains insufficient. AntiHBs-negative children may be at a higher risk of HBV infection in $\mathrm{HBV}$ endemic countries including Indonesia. An effective strategy needs to be developed to detect all vaccination failure cases in order to achieve the complete control of HBV infection. To achieve complete protection, it would be necessary to consider an appropriate time for the first dose and booster dose.

\section{Acknowledgments}

This study was supported by a Grant-in-Aid from the Japan Initiative for Global Research Network on Infectious Diseases (JGRID) program from the Ministry of Education, Culture, Sports, Science, and Technology (MEXT), Japan. We would like to thank the health center at East Perak for sample collection.

\section{References}

1. Creati M, Saleh A, Ruff TA, Stewart T, Otto B, et al. (2007) Implementing the birth dose of hepatitis B vaccine in rural Indonesia. Vaccine 25: 5985-5993.

2. Ott JJ, Stevens GA, Groeger J, Wiersma ST (2012) Global epidemiology of hepatitis B virus infection: new estimates of age-specific HBsAg seroprevalence and endemicity. Vaccine 30: 2212-2219.

3. Cho Y, Bonsu G, Akoto-Ampaw A, Nkrumah-Mills G, Nimo JJ, et al. (2012) The prevalence and risk factors for hepatitis B surface ag positivity in pregnant women in eastern region of ghana. Gut Liver 6: 235-240.

4. Wang L, Li J, Chen H, Li F, Armstrong GL, et al. (2007) Hepatitis B vaccination of newborn infants in rural China: evaluation of a villagebased, out-of-cold-chain delivery strategy. Bull World Health Organ 85: 688-694.

5. Hennessey K, Mendoza-Aldana J, Bayutas B, Lorenzo-Mariano KM, Diorditsa S (2013) Hepatitis B control in the World Health Organization's Western Pacific Region: targets, strategies, status. Vaccine 31: J85-92.

6. Clements CJ, Baoping Y, Crouch A, Hipgrave D, Mansoor O, et al. (2006) Progress in the control of hepatitis B infection in the Western Pacific Region. Vaccine 24: 1975-1982.

7. Danielsson N, Fakakovikaetau T, Szegedi E (2009) Improved immunization practices reduce childhood hepatitis B infection in Tonga. Vaccine 27: 4462-4467.

8. Mao B, Patel MK, Hennessey K, Duncan RJ, Wannemuehler K, et al. (2013) Prevalence of chronic hepatitis B virus infection after implementation of a hepatitis $B$ vaccination program among children in three provinces in Cambodia. Vaccine 3: 4459-4464.

9. Levin CE, Nelson CM, Widjaya A, Moniaga V, Anwar C (2005) The costs of home delivery of a birth dose of hepatitis $\mathrm{B}$ vaccine in a prefilled syringe in Indonesia. Bull World Health Organ 83: 456-461.

10. Nelson C, Widjaya A, Wittet S (2002) Using Uniject to increase the safety and effectiveness of hepatitis B Immunization. PATH's Children's Vaccine Program. 
Citation: Utsumi T, Lusida MI, Yano Y, Purwono PB, Amin M, et al. (2014) Progress in the Control of Hepatitis B Virus Infection among Children in Indonesia . J Vaccines Vaccin 5: 247. doi:/10.4172/2157-7560.1000247

Page 6 of 6

11. Abe A, Inoue K, Tanaka T, Kato J, Kajiyama N, et al. (1999) Quantitation of hepatitis B virus genomic DNA by real-time detection PCR. J Clin Microbiol 37: 2899-2903.

12. Hasan I (2005) Epidemiology of hepatitis B. Acta Med Indones 37: 231-234.

13. Ni YH, Chang MH, Wu JF, Hsu HY, Chen HL, et al. (2012) Minimization of hepatitis $\mathrm{B}$ infection by a 25 -year universal vaccination program. J Hepatol 57: 730-735.

14. UNICEF (2013) Immunization Summary 2011. WHO.

15. Franco E, Bagnato B, Marino MG, Meleleo C, Serino L, et al. (2012) Hepatitis B: Epidemiology and prevention in developing countries. World J Hepatol 4: 74-80.

16. Utsumi T, Yano Y, Lusida MI, Amin M, Soetjipto, et al. (2010) Serologic and molecular characteristics of hepatitis B virus among school children in East Java, Indonesia. Am J Trop Med Hyg 83: 189-193.

17. Pande C, Sarin SK, Patra S, Kumar A, Mishra S, et al. (2013) Srivastava S, Bhutia K, Gupta E, Mukhopadhyay CK, Dutta AK and Trivedi SS: Hepatitis B vaccination with or without hepatitis B immunoglobulin at birth to babies born of HBsAg-positive mothers prevents overt HBV transmission but may not prevent occult HBV infection in babies: a randomized controlled trial. J Viral Hepat 20: 801-810.

18. Mu SC, Lin YM, Jow GM, Chen BF (2009) Occult hepatitis B virus infection in hepatitis B vaccinated children in Taiwan. J Hepatol 50: 264-272.

19. http://www.biofarma.co.id/

20. Mendy M, Peterson I, Hossin S, Peto T, Jobarteh ML, et al. (2013) Observational study of vaccine efficacy 24 years after the start of hepatitis $B$ vaccination in two Gambian villages: no need for a booster dose. PLoS One 8: e58029.
21. Chaves SS, Groeger J, Helgenberger L, Auerbach SB, Bialek SR, et al. (2010) Improved anamnestic response among adolescents boosted with a higher dose of the hepatitis B vaccine. Vaccine 28: 2860-2864.

22. WHO (2013) Practices to improve coverage of the hepatitis B birth dose vaccine. Immunization Vaccine and Biologicals.

23. Kfoury Baz EM, Zheng J, Mazuruk K, Van Le A, Peterson DL (2001) Characterization of a novel hepatitis B virus mutant: demonstration of mutation-induced hepatitis B virus surface antigen group specific "a" determinant conformation change and its application in diagnostic assays. Transfus Med 11: 355-362.

24. Basuni AA, Butterworth L, Cooksley G, Locarnini S, Carman WF (2004) Prevalence of HBsAg mutants and impact of hepatitis B infant immunisation in four Pacific Island countries. Vaccine 22: 2791-2799.

25. Shahmoradi S, Yahyapour Y, Mahmoodi M, Alavian SM, Fazeli Z, et al. (2012) High prevalence of occult hepatitis B virus infection in children born to HBsAg-positive mothers despite prophylaxis with hepatitis B vaccination and HBIG. J Hepatol 57: 515-521.

26. Chen CY, Hsu HY, Liu CC, Chang MH, Ni YH (2010) Stable seroepidemiology of hepatitis B after universal immunization in Taiwan: A 3-year study of national surveillance of primary school students. Vaccine 28: 5605-5608.

27. Clements CJ, Coghlan B, Creati M, Locarnini S, Tedder RS, et al. (2010) Global control of hepatitis B virus: does treatment-induced antigenic change affect immunization? Bull World Health Organ 88: 66-73.

28. Png E, Thalamuthu A, Ong RT, Snippe H, Boland GJ, et al. (2011) A genome-wide association study of hepatitis $\mathrm{B}$ vaccine response in an Indonesian population reveals multiple independent risk variants in the HLA region. Hum Mol Genet 20: 3893-3898. 